\title{
Efeito de diferentes níveis de farelo de gérmen de milho desengordurado em dietas suplementadas com fitase para poedeiras comerciais
}

\section{Effect of different inclusion levels of defatted corn germ meal in diets supplemented with phytase for laying hens}

\author{
Sandra Regina Brunelli ${ }^{1}$; João Waine Pinheiro ${ }^{2 *}$; \\ Nilva Aparecica Nicolao Fonseca ${ }^{3}$; Caio Abércio da Silva ${ }^{2}$
}

\begin{abstract}
Resumo
O experimento foi realizado com objetivo de avaliar o desempenho, a qualidade dos ovos e a concentração de minerais na tíbia de poedeiras leves alimentadas com rações contendo farelo de gérmen de milho desengordurado (FGMD) e fitase. Foram utilizadas 360 poedeiras de 28 a 44 semanas de idade. As rações experimentais continham diferentes inclusões de FGMD $(0 \%, 12 \%$ e $30 \%)$ e de fitase $(0 ; 500$ e $1000 \mathrm{FTU} / \mathrm{kg}$ ), distribuídos em um delineamento experimental inteiramente casualizado em fatorial $3 \mathrm{X}$ 3 , totalizando nove rações, com cinco repetições e oito aves por repetição. O experimento teve a duração de quatro ciclos de 28 dias cada, em que foram avaliados consumo de ração, produção, massa e peso médio dos ovos, conversão alimentar, gravidade específica, índice de pigmentação de gema, unidade Haugh e espessura da casca. Ao final do experimento foram abatidas cinco aves por ração experimental para determinar os teores de $\mathrm{Ca}$ e $\mathrm{P}$ e a relação Ca:P na tíbia. Não foram observadas interações entre as rações experimentais para os parâmetros estudados. Houve efeito significativo dos níveis de FGMD no consumo de ração e na pigmentação das gemas. Observou-se também efeito positivo da adição de 1000 FTU/kg na ração na pigmentação das gemas. O FGMD pode compor $30 \%$ da ração das poedeiras desde que haja a suplementação de pigmentantes da gema. A fitase melhora a coloração das gemas.
\end{abstract}

Palavras-chave: Alimento alternativo, enzima, nutrição, qualidade de ovos

\begin{abstract}
The experiment was designed to evaluate the performance, egg quality and minerals on tibia of laying hens from 28 to 44 weeks of age subjected to diets containing varying levels of DCGM $(0,12$ and 30\%) and phytase $(0,500$ and $1000 \mathrm{FTU} / \mathrm{kg}$ of diet). The experiment was carried in four cycles of 28 days and the variables studied were: the performance (feed intake, egg production, egg weight, egg mass and feed conversion) and egg quality (egg specific gravity, yolk color, shell thickness and Haugh unity value). In the finish of experiment, five birds per treatment were abated for determination of the calcium and phosphorus in tibia. There was no interaction between DCGM and phytase on evaluated parameters. Inclusion of DCGM resulted in significantly higher feed intake and worst yolk pigmentation, than the $0 \%$ treatment. Increasing the phytase dose to $1000 \mathrm{FTU} / \mathrm{kg}$ improves yolk pigmentation. For the others variables no effect were observed for levels of DCGM or phytase. Based on the results from
\end{abstract}

${ }^{1}$ Prof $^{a}$. Drª da Faculdade de Ciências Sociais e Agrárias de Itapeva, FAIT, Itapeva, SP. E-mail: sandrareginabrunelli@hotmail. com

${ }^{2}$ Profs. Drs. do Dept ${ }^{\circ}$ de Zootecnia da Universidade Estadual de Londrina, UEL, Londrina, PR. E-mail: jwaine@uel.br; casilva@ uel.br

${ }^{3}$ Prof $^{\mathrm{a}}$. Dr ${ }^{\mathrm{a}}$ Aposentada do Dept ${ }^{\circ}$ de Zootecnia, UEL, Londrina, PR. E-mail: nilva@uel.br

* Autor para correspondência 
the present study, DCGM could be included at a rate of up to $30 \%$ of a commercial layer diets without any significant detrimental effects on the egg production, but with yolk pigment addition. The phytase improve the yolk color.

Key words: Alternative feed, egg quality, enzyme, nutrition

\section{Introdução}

$\mathrm{O}$ farelo de gérmen de milho desengordurado (FGMD), produto da extração do óleo do gérmen do milho, apresenta potencial de uso na alimentação de poedeiras, embora seu valor nutricional seja inferior ao do milho. O produto também possui alta concentração de ácido fítico, quantificado por Fukuji et al. (2008) em 2,81\%, o que constitui um aspecto negativo para o seu uso na alimentação de animais monogástricos.

O ácido fítico (mio-inositol hexafosfato) é um componente encontrado na maioria dos vegetais e, devido a sua habilidade em formar complexos insolúveis com importantes minerais (cálcio, ferro, zinco e magnésio) e influenciar negativamente na utilização da energia e da proteína da ração, é considerado um fator antinutricional (RAVINDRAN et al., 2006; SELLE; RAVINDRAN, 2007). Na indústria alimentícia, dada sua capacidade de quelatar o ferro, é usado diretamente na carne como antioxidante natural (LEE; HENDRICKS, 1995; SOARES et al., 2004).

Todavia, priorizando a eficiência no aproveitamento dos nutrientes das rações para aves, e reconhecendo a elevada concentração de ácido fítico nos grãos, a utilização da enzima fitase tem sido ampliada comercialmente.

A fitase (mio-inositol hexafosfato fosfohidrolase) tem como função hidrolisar a molécula do ácido fítico e disponibilizar principalmente o fósforo para as aves, reduzindo a sua excreção. No entanto, o seu efeito na utilização da energia e dos aminoácidos não está claro (SELLE; RAVINDRAN, 2007).

Alguns estudos já demonstraram a eficácia da enzima fitase no desempenho e na disponibilidade do cálcio e do fósforo em poedeiras comerciais alimentadas com ração à base de milho e farelo de soja (LIM; NAMKUNG; PAIK, 2003; PANDA et al.,
2005; WU et al., 2006). Além de proporcionar menor incidência de ovos de casca fina, a sua utilização resulta em aumento na absorção dos pigmentos, na massa de ovos e melhora da quantidade de albúmen e da gema (SOTO-SALANOVA; WATT, 1997).

Deste modo, objetivou-se avaliar os efeitos de rações formuladas à base de milho e farelo de soja, com diferentes inclusões de FGMD e de fitase, no desempenho produtivo, qualidade dos ovos e o percentual de cálcio e fósforo na tíbia de poedeiras de 28 a 44 semanas de idade.

\section{Material e Métodos}

O experimento foi conduzido no Setor de Avicultura da Fazenda Escola da Universidade Estadual de Londrina. Foram utilizadas 360 poedeiras, com 28 semanas de idade, durante 112 dias, compreendendo quatro ciclos de 28 dias.

As poedeiras foram alojadas em 45 gaiolas com oito aves cada, constituindo a unidade experimental. Durante o experimento as aves tiveram livre acesso a água e ração, e utilizou-se um programa de iluminação com 17 horas de luz/dia.

$\mathrm{O}$ delineamento experimental utilizado foi o inteiramente casualizado, em esquema fatorial $3 \times 3$, em que os fatores constituíram de rações experimentais isonutritivas, à base de milho e farelo de soja, contendo três níveis de inclusão de FGMD $(0 ; 12$ e $30 \%)$ e três níveis de inclusão de fitase $(0 ; 500$ e $1000 \mathrm{FTU} / \mathrm{kg})$, resultando em nove rações, cada uma com cinco repetições de oito aves. As rações experimentais (Tabela 1) foram formuladas utilizando as composições bromatológicas nutricionais dos alimentos e as exigências nutricionais mínimas para poedeiras preconizadas por Rostagno et al. (2005), à exceção do FGMD cujos valores nutritivos considerados foram os determinados por Brunelli et al. (2006). 
Tabela 1. Composição das rações experimentais.

\begin{tabular}{lrcc}
\hline \multirow{2}{*}{ Ingrediente } & \multicolumn{3}{c}{ Nível de inclusão do FGMD (\%) } \\
\cline { 2 - 4 } Milho & 0 & 12 & 30 \\
Farelo de soja & 63,79 & 51,00 & 31,82 \\
FGMD & 22,93 & 21,77 & 19,97 \\
Óleo de soja & 0,00 & 12,00 & 30,00 \\
Fosfato bicálcico & 1,48 & 3,40 & 6,28 \\
Calcário & 1,52 & 1,42 & 1,28 \\
Sal comum & 9,25 & 9,25 & 9,26 \\
DL-Metionina (99\%) & 0,48 & 0,48 & 0,50 \\
L-Lisina HCl (79\%) & 0,15 & 0,22 & 0,31 \\
Suplemento vit.+min.+AA ${ }^{1}$ & 0,00 & 0,05 & 0,15 \\
Total & 0,40 & 0,40 & 0,40 \\
\hline Composição calculada & 100,00 & 100,00 & 100,00 \\
Energia metabolizável (kcal/kg) & & & 2.800 \\
Proteína bruta (\%) & 2.800 & 2.800 & 16,00 \\
Cálcio (\%) & 16,00 & 16,00 & 4,02 \\
Fósforo disponível (\%) & 4,02 & 4,02 & 0,37 \\
Lisina digestível (\%) & 0,37 & 0,37 & 0,70 \\
Metionina + cistina digestível (\%) & 0,70 & 0,70 & 0,61 \\
Fibra bruta (\%) & 0,61 & 0,61 & 3,48 \\
Gordura (\%) & 2,60 & 2,96 & 8,24 \\
\hline
\end{tabular}

${ }^{1}$ Suplemento vitamínico- mineral -aminoácido, por kg de produto: Vit. A 2.500.000 UI, Vit. B1 350 mg, Vit. B12 2.750 mcg, Vit B2 $1.250 \mathrm{mg}$, Vit B6 $500 \mathrm{mg}$, D3 625.000 UI, Vit. E $1.500 \mathrm{mg}$, Vit. K $400 \mathrm{mg}$, Ácido fólico $100 \mathrm{mg}$, Ácido pantotênico $2.500 \mathrm{mg}$, Cobre $2.000 \mathrm{mg}$, Ferro $12.500 \mathrm{mg}$, Zinco 12.500, Iodo 187,5 mg, Mangânes $18.750 \mathrm{mg}$, Metionina 172,5 g, Niacina 6.250 mg, Selênio $75 \mathrm{mg}$, Antioxidante 2,5 g e Veículo Q.S.P $1.000 \mathrm{~g}$.

Fonte: Elaboração dos autores.

A fitase utilizada foi o produto NATUPHOS $10.000 \mathrm{G}^{\circledR}$, sendo as rações formuladas sem considerar a sua matriz nutricional.

Diariamente foram registradas a produção de ovos e a mortalidade das aves em cada unidade experimental e nos dois últimos dias de cada ciclo foram avaliados: o consumo de ração (CR), em g/ ave/dia; o peso médio dos ovos (PMO), em g; a massa de ovos (MO), em g/ave/dia e a conversão alimentar (CA),em g de ração/g de massa ovo. Foram também avaliadas as características de qualidade dos ovos: gravidade específica $\left(\mathrm{g} / \mathrm{cm}^{3}\right)$; índice de pigmentação da gema; espessura de casca (mm) e unidade Haugh (UH).

Em cada parcela o consumo de ração foi calculado pela diferença entre o fornecido no início e a sobra ao final de cada ciclo 28 dias, sendo o consumo de cada ave determinado dividindo-se o consumo de ração na parcela pelo número de aves, e nas parcelas que ocorreram mortes, dividiu-se o consumo pela média ponderada de aves no período. A produção de ovos, registrada diariamente, foi calculada em porcentagem ao final de cada ciclo. O peso médio dos ovos foi obtido através do peso total dos mesmos dividido pela produção nos dois últimos dias de cada ciclo. A massa de ovos correspondeu ao produto do número de ovos pelo peso médio dos ovos da parcela. A conversão alimentar por massa de ovo foi calculada através da relação entre o consumo de ração e a massa de ovo produzida.

Os ovos íntegros de cada unidade experimental foram mergulhados em sete soluções salinas com densidade variando de 1,080 a $1,098 \mathrm{~g} / \mathrm{cm}^{3}$, 
com gradiente de 0,003 entre elas, para estimar a gravidade específica, conforme técnica de flutuação proposta por Hamilton (1982).

Posteriormente, dois ovos de cada unidade experimental foram identificados, pesados e quebrados, obtendo-se a cor da gema, através do abanico colorimétrico da Roche. Após separação e lavagem, as cascas ficaram expostas por 72 horas à temperatura ambiente para determinação da sua espessura, através de um paquímetro digital.

Também foi obtida a altura do albúmen, através de micrometro, para a realização do cálculo da unidade Haugh, utilizando a fórmula proposta por Stadelman e Cotteril (1986), UH= $100 \times \log (\mathrm{H}+$ $7,57-1,7 \mathrm{~W}^{0,37}$ ), em que: $\mathrm{H}=$ altura do albúmen $(\mathrm{mm}) ; 7,57=$ fator de correção para altura do albúmen; 1,7 = fator de correção para peso do ovo e $\mathrm{W}=$ peso do ovo $(\mathrm{g})$.

Ao final do experimento foi sacrificada, por deslocamento cervical, uma ave por unidade experimental e da tíbia esquerda foram determinados os teores de cálcio e fósforo, conforme a metodologia descrita por Silva e Queiroz (2002).

As médias dos parâmetros analisados foram submetidas à análise de variância através do programa SAEG, (UFV, 2000), com derivação de polinômios. Para comparação das médias obtidas em cada nível de FGMD e de fitase, em relação à ração testemunha, foi utilizado o teste Dunnett $(5 \%)$.

\section{Resultados e Discussão}

Não houve interação significativa $(\mathrm{P}>0,05)$ entre os níveis do FGMD e os de fitase para as variáveis analisadas.

Com relação ao desempenho produtivo (Tabela 2), verifica-se que o consumo da ração com $30 \%$ de FGMD foi inferior ao da ração controle $(\mathrm{P}<0,05)$, não sendo observados efeitos dos diferentes níveis de FGMD e de fitase sobre as demais características estudadas.

Tabela 2. Desempenho de poedeiras de 28 a 44 semanas de idade alimentadas com rações com diferentes níveis de farelo de gérmen de milho desengordurado (FGMD) e fitase.

\begin{tabular}{|c|c|c|c|c|c|c|c|}
\hline \multirow{2}{*}{ Características } & \multicolumn{3}{|c|}{ FGMD (\%) } & \multicolumn{3}{|c|}{ Fitase (FTU/kg) } & \multirow{2}{*}{$\begin{array}{l}\text { C. }{ }^{1} \\
(\%)\end{array}$} \\
\hline & 0 & 12 & 30 & 0 & 500 & 1000 & \\
\hline Consumo de ração (g/ave/d) & 102,84 & 100,83 & $99,20^{*}$ & 101,43 & 101,67 & 99,77 & 3,58 \\
\hline Produção de ovos (\%) & 94,54 & 93,77 & 93,18 & 94,65 & 94,01 & 92,83 & 4,89 \\
\hline Peso médio dos ovos (g) & 59,93 & 59,94 & 59,71 & 59,77 & 59,96 & 59,85 & 2,82 \\
\hline Massa de ovos (g/ave/d) & 56,65 & 56,19 & 55,56 & 56,54 & 56,37 & 55,50 & 4,94 \\
\hline Conversão alimentar $(\mathrm{g} / \mathrm{g})$ & 1,82 & 1,80 & 1,79 & 1,79 & 1,81 & 1,81 & 5,62 \\
\hline
\end{tabular}

${ }^{1}$ Coeficiente de Variação; *Valor diferente $(\mathrm{P}<0,05)$ em relação à ração testemunha pelo teste de Dunnett.

Fonte: Elaboração dos autores.

Os níveis crescentes de FGMD exigiram aumento de óleo de soja nas formulações, a fim de garantir a concentração energética das rações, o que pode ter proporcionado a redução no consumo para o maior nível do farelo. A redução no consumo de rações acrescidas de gordura se explica pela diminuição na taxa de passagem do alimento pelo trato gastrintestinal (MATEOS; SELL, 1981;
MATEOS; SELL; EASTWOOD, 1982). Em estudos com poedeiras alimentadas com rações contendo componentes fibrosos, farelo de arroz ou farelo de coco, Samli et al. (2006) e Lima et al. (2007) também observaram redução nos consumos, o que associaram à correção da energia pela adição de óleo vegetal. 
Quanto a fitase, os resultados obtidos estão em consonância com os de Tangendjaja, Chung e Broz (2002) que também não encontraram efeitos no consumo quando alimentaram poedeiras de 23 a 48 semanas de idade com ração contendo farelo de arroz, alimento fibroso rico em acido fítico, acrescida ou não de fitase.

O efeito da fitase sobre o consumo de ração das poedeiras está relacionado à sua concentração de fósforo. Liu et al. (2007) confirmou esta hipótese ao verificar que poedeiras alimentadas com uma ração controle positivo contendo $3,30 \% \mathrm{Ca}$ e $0,28 \% \mathrm{P}$ disponível (Pd) consumiram mais que as alimentadas com uma ração controle negativo contendo $3,18 \%$ $\mathrm{Ca}$ e $0,15 \% \mathrm{Pd}$, e semelhante às alimentadas com a ração controle negativo suplementada com 300 FTU/kg.

Borrmann et al. (2001) também relataram que a adição da fitase aumentou o consumo de rações deficientes em fósforo disponível $(0,1 \% \mathrm{Pd})$, não diferindo das rações com níveis elevados deste elemento $(0,3$ e $0,4 \%$ Pd). Godoy, Hernández e Chicco (2002) verificaram que a atividade da enzima fitase é inibida com o aumento do fósforo inorgânico na ração.

Não houve efeito significativo $(\mathrm{P}>0,05)$ dos níveis de FGMD e de fitase na produção de ovos, concordando com os resultados obtidos por Tangendjaja, Chung e Broz (2002).

Trabalhos conduzidos por Silversides et al. (2006) em que foram estudados diferentes níveis de fitase $(0,300,500$ e $700 \mathrm{FTU} / \mathrm{kg}$ de ração) e de fósforo disponível $(0 ; 20$ e $0,30 \%)$ em rações à base de milho e farelo de soja para poedeiras de 34 a 49 semanas de idade, também não demonstraram efeitos da enzima na produção de ovos.

Algumas pesquisas evidenciaram efeito negativo doácido fítico da dieta sobre as proteases, interferindo na digestibilidade das proteínas e dos aminoácidos (WEAVER; KANNAN, 2002; RAVINDRAN et al., 2006). Por ser o FGMD um alimento rico em ácido fítico, esperava-se um resultado negativo dos seus níveis de inclusão no peso dos ovos, já que este é determinado pela ingestão de proteína, contudo este efeito não foi confirmado. O’Dell e Del Boland (1976) demonstraram que o ácido fítico não forma complexos fortes com as proteínas do milho.

Em seus estudos Jalal e Scheideler (2001) observaram semelhanças no peso dos ovos quando as poedeiras foram alimentadas com rações suplementadas ou não com fitase. No entanto, outros trabalhos demonstraram que a suplementação com fitase causa melhora significativa nesta característica (CEYLAN; SCHEIDELER; STILBORN, 2003; WU et al., 2006; SILVERSIDES et al., 2006). Segundo Ceylan, Scheideler e Stilborn (2003) o efeito da fitase sobre o peso dos ovos está relacionado ao consumo de fósforo disponível, sugerindo que a sua ingestão diária inferior a $300 \mathrm{mg}$ pode ser insuficiente para garantir os pesos adequados dos ovos. Estes mesmos autores observaram que $200 \mathrm{mg}$ de $\mathrm{Pd} /$ dia foi suficiente para manter o peso dos ovos somente para as dietas suplementadas com fitase (300 FTU/kg de ração). A deficiência de fósforo da dieta, portanto, afeta negativamente a qualidade e o peso dos ovos (GUILLERMO et al., 2004).

A massa do ovo não foi afetada pela inclusão do FGMD e de fitase nas rações ( $\mathrm{P}>0,05)$, o que se explica pelo fato de que as variáveis envolvidas no cálculo desta variável (peso médio do ovo e número de ovos) não terem sido influenciadas pelas rações experimentais.

Não foram observados efeitos significativos $(\mathrm{P}>0,05)$ das rações experimentais na conversão alimentar. Muito embora tenha havido diferença significativa no consumo da ração com $30 \%$ de FGMD, em relação à ração testemunha, esta não foi suficiente para reduzir a massa de ovos, não afetando a conversão alimentar.

Com relação a fitase, os resultados obtidos corroboram com os de Lim, Namkung e Paik (2003), que também não encontraram efeito da enzima para a conversão alimentar. 
Portanto, a concentração de $0,37 \%$ Pd nas rações utilizadas neste experimento, que correspondeu ao consumo médio de $378 \mathrm{mg}$ de fósforo disponível/ ave/dia, foi suficiente para atender as exigências nutricionais, não havendo efeito do fósforo liberado pela fitase sobre os parâmetros produtivos considerados.

A gravidade específica dos ovos não foi afetada $(\mathrm{P}>0,05)$ pelos níveis de FGMD e da fitase nas rações (Tabela 3).

Tabela 3. Efeito dos diferentes níveis de farelo de gérmen de milho desengordurado (FGMD) e fitase na ração de poedeiras sobre a qualidade dos ovos.

\begin{tabular}{|c|c|c|c|c|c|c|c|}
\hline \multirow{2}{*}{ Características } & \multicolumn{3}{|c|}{ FGMD (\%) } & \multicolumn{3}{|c|}{ Fitase (FTU/kg) } & \multirow{2}{*}{$\begin{array}{l}\text { C.V }{ }^{1} \\
(\%)\end{array}$} \\
\hline & 0 & 12 & 30 & 0 & 500 & 1000 & \\
\hline Gravidade específica $\left(\mathrm{g} / \mathrm{cm}^{3}\right)$ & 1,089 & 1,089 & 1,089 & 1,089 & 1,089 & 1,089 & 0,08 \\
\hline Cor da gema & 6,56 & $6,08^{*}$ & $4,94 *$ & 5,64 & 5,92 & $6,00^{*}$ & 6,90 \\
\hline Espessura da casca (mm) & 40,08 & 40,24 & 40,39 & 40,24 & 40,38 & 40,08 & 1,95 \\
\hline Unidade Haugh & 94,01 & 93,07 & 92,84 & 94,01 & 93,26 & 92,65 & 2,79 \\
\hline
\end{tabular}

${ }^{1}$ Coeficiente de variação; *Valor diferente $(\mathrm{P}<0,05)$ em relação à ração testemunha pelo teste de Dunnett.

Fonte: Elaboração dos autores.

Com relação ao FGMD, os resultados se opõem aos de Fireman, Fireman e Lopez (1999) e Araújo et al. (2008) que, pesquisando farelo de trigo na dieta de poedeiras, encontraram influência negativa do elevado teor de ácido fítico na gravidade específica dos ovos, que melhorou com a adição de fitase (300 e 600 FTU/ kg) (FIREMAN; FIREMAN; LOPEZ,1999).

Segundo Gordon e Roland (1998) e Keshavarz (2000), a gravidade específica dos ovos está relacionada com os níveis de cálcio e fósforo da dieta. Gordon e Roland (1998) determinaram melhora na gravidade específica quando alimentaram as poedeiras com dietas contendo níveis elevados de cálcio, enquanto que Keshavarz (2000) constatou melhora para dietas com baixo nível de fósforo disponível, adicionada de fitase.

A cor da gema apresentou diferenças significativas nas inclusões de 12 e $30 \%$ de FGMD $(\mathrm{P}<0,05)$ em relação à testemunha. Certamente isto ocorreu pela menor oferta do pigmento xantofila, que no grão de milho está em maior concentração $(20,09 \mu \mathrm{g} / \mathrm{g})$ do que o gérmen $(1,88 \mu \mathrm{g} / \mathrm{g})$ (MOROS et al., 2002).
A utilização de alimentos alternativos ao milho e ao farelo de soja para compor as rações das poedeiras deve levar em consideração a pigmentação da gema, que é influenciada pela quantidade de xantofila neles contida (ACKER; CUNNINGHAM, 1991). Normalmente há preferência, por parte do consumidor, pelas gemas com tons mais alaranjados. Brito et al. (2005) ao alimentarem galinhas poedeiras com rações contendo farelo de gérmen de milho também encontraram diminuição na pigmentação das gemas. De acordo com Brito e Stringhini (2003) não há necessidade de adicionar pigmentantes na ração quando as gemas atingem o escore cinco, ou superior, na escala Roche. Portanto, observa-se que a inclusão de $30 \%$ de FGMD proporcionou gemas abaixo do score aceitável pelo consumidor.

Com relação à suplementação de fitase, as aves alimentadas com as rações contendo 1000 FTU/ $\mathrm{kg}$ apresentaram ovos com gemas mais alaranjadas em relação às alimentadas com rações sem fitase. Este resultado pode estar relacionado à hidrólise do ácido fítico da dieta pela fitase. O ácido fítico tem propriedade despigmentante e antioxidante e é utilizado na composição de cremes clareador cutâneo (GARDONI et al., 2004). Soto-Salanova 
e Watt (1997) relataram que um dos efeitos da suplementação da enzima fitase às dietas de poedeiras é o aumento na absorção dos pigmentos.

Observa-se que a espessura da casca e a unidade Haugh não foram influenciadas $(\mathrm{P}>0,05)$ pelos níveis de FGMD e de fitase. Brito et al. (2005) também não encontraram efeitos da inclusão de gérmen de milho integral na ração sobre estes parâmetros de qualidade dos ovos em poedeiras comerciais. Os efeitos da fitase sobre a espessura da casca estão de acordo com os resultados obtidos por Ceylan, Scheideler e Stilborn (2003), mas diferem dos observados por Borrmann et al. (2001) que encontraram piora na espessura da casca $(0,359 \mathrm{~mm})$ quando as poedeiras foram alimentadas com rações suplementadas com fitase, quando comparada com as rações não suplementadas $(0,368 \mathrm{~mm})$.

A unidade Haugh constitui importante medida da qualidade interna do ovo, e de acordo com
Jensen, Shang e Wilson (1978) é influenciada pela disponibilidade de elementos traços nos alimentos. Loar et al. (2010) estudando DDGS (distiller's dried grains with solubles), subproduto da indústria do etanol de milho, na alimentação de poedeiras, observaram aumento da unidade Haugh dos ovos, o que também atribuíram ao aumento da disponibilidade de elementos traços no produto, resultante da remoção do amido do grão de milho. O FGMD utilizado neste experimento também constitui subproduto da indústria de milho, contendo baixa concentração de amido, o que indicaria maior concentração de elementos traços na ração, que não foram suficientes para suportar os achados de Jensen, Shang e Wilson (1978) e Loar et al. (2010).

Não houve diferença significativa $(\mathrm{P}>0,05)$ entre as concentrações de cálcio, fósforo e da relação cálcio:fósforo na tíbia das poedeiras, para as rações experimentais (Tabela 4).

Tabela 4. Cálcio, fósforo e relação de cálcio: fósforo na tíbia de poedeiras alimentadas com farelo de gérmen de milho desengordurado (FGMD) e fitase.

\begin{tabular}{|c|c|c|c|c|c|c|c|}
\hline \multirow{2}{*}{ Características (\%) } & \multicolumn{3}{|c|}{ FGMD (\%) } & \multicolumn{3}{|c|}{ Fitase (FTU/kg) } & \multirow{2}{*}{$\begin{array}{l}\text { C. } V^{1} \\
(\%)\end{array}$} \\
\hline & 0 & 12 & 30 & 0 & 500 & 1000 & \\
\hline Cálcio & 17,02 & 16,94 & 16,60 & 16,78 & 16,95 & 16,83 & 3,62 \\
\hline Fósforo & 9,43 & 9,20 & 9,24 & 9,17 & 9,26 & 9,35 & 6,74 \\
\hline Cálcio:fósforo & 1,83 & 1,85 & 1,80 & 1,84 & 1,84 & 1,81 & 8,40 \\
\hline
\end{tabular}

${ }^{1}$ Coeficiente de variação.

Fonte: Elaboração dos autores.

Os dados indicam que a quantidade de ácido fítico presente no FGMD não interferiu na deposição de cálcio e de fósforo na tíbia, evidenciando que as quantidades destes elementos contidas nas rações foram suficientes para a manutenção das estruturas ósseas das aves. No entanto, Vieira et al. (2001) observaram que as tíbias dos frangos alimentados com ração contendo farelo de arroz ou farelo de trigo apresentaram menor percentual de fósforo $(10,47 \%)$ em relação aos alimentadas com milho e soja $(11,12 \%)$, o que atribuíram às concentrações de ácido fítico.
Com relação à fitase dietética, os resultados obtidos concordam com os de Pintar et al. (2005), que encontraram ausência de efeitos da adição desta enzima na ração (500 ou $1000 \mathrm{FTU} / \mathrm{kg}$ de ração) nas concentrações de $\mathrm{Ca}$ e de $\mathrm{P}$ das tíbias de frangos, mas contrariam os de Vieira et al. (2007), que determinaram maior concentração do fósforo na tíbia dos frangos alimentados com rações à base de milho e farelo de soja, quando comparados com os alimentados com rações contendo milho, farelo de soja, farelo de trigo integral e fitase. 
A relação de $\mathrm{Ca}: P$ na tíbia não foi influenciada $(\mathrm{P}>0,05)$ pelos níveis de inclusão de FGMD ou de fitase na ração. Segundo Scott, Nesheim e Young (1982), a relação de Ca:P nos ossos das poedeiras deve ser em torno de 2:1, valor acima do encontrado neste trabalho.

\section{Conclusão}

Os resultados deste experimento mostraram que o farelo de gérmen de milho desengordurado pode compor até $30 \%$ da dieta das poedeiras leves, desde que sejam observados os aspectos relativos à pigmentação das gemas dos ovos. A fitase não foi efetiva em alterar a eficiência produtiva, a qualidade dos ovos e a mineralização das tíbias das poedeiras, contudo a adição de 1000 FTU /kg de ração proporcionou gema mais alaranjada, atributo que o consumidor associa à sua qualidade.

\section{Referências}

ACKER, D.; CUNNINGHAM, M. Animal science and industry. 4. ed. Englewood Cliffs: Prentice-Hall, 1991. $709 \mathrm{p}$.

ARAÚJO, D. M.; SILVA, J. H. V.; ARAUJO, J. A.; TEIXEIRA, E. N. M.; JORDÃO FILHO, J.; RIBEIRO, M. L. G. Farelo de trigo na alimentação de poedeiras semipesadas na fase de recria. Revista Brasileira de Zootecnia, Viçosa, v. 37, n. 1, p. 67-72, 2008.

BORRMANN, M. S. L.; BERTECHINI, A. G.; FIALHO, E. T.; OLIVEIRA, B. L. Efeito da adição de fitase com diferentes níveis de fósforo disponível em rações de poedeiras de segundo ciclo. Revista Ciência e Agrotecnologia, Lavras, v. 25, n. 1, p. 181-187, 2001.

BRITO, A. B.; STRINGHINI, J. H. Avaliação do gérmen integral de milho na nutrição de poedeiras comerciais. Avicultura Industrial, Itu, n. 10, p. 22-24, 2003.

BRITO, A. B.; STRINGHINI, J. H.; BELEM, L. M.; XAVIER, S. A. G.; LEANDRO, N. S. M.; CAFÉ, M. B. Desempenho e qualidade dos ovos de poedeiras comerciais de 30 a 64 semanas de idade consumindo gérmen integral de milho. Acta Scientiarum. Animal Sciences, Maringá, v. 27, n. 1, p. 29-34, 2005.

BRUNELLI, S. R.; PINHEIRO, J. W.; SILVA, C. A.; FONSECA, N. A. N.; OLIVEIRA, D. D.; CUNHA, G.
E.; SOUZA, L. F. A. Inclusão de farelo de gérmen de milho desengordurado na alimentação de frangos de corte. Revista Brasileira de Zootecnia, Viçosa, v. 35, n. 4, p. 1349-1358, 2006.

CEYLAN, N.; SCHEIDELER, S. E.; STILBORN, H. L. High available phosphorus corn and phytase on layer diets. Poultry Science, Champaign, v. 82, n. 5, p. 789795, 2003.

FIREMAN, A. K. B. A. T.; FIREMAN, F. A. T.; LOPEZ, J. Efeito da fitase sobre a qualidade da casca do ovo de poedeiras alimentadas com dietas baseadas em farelo de arroz desengordurado. In: REUNIÃO ANUAL DA SOCIEDADE BRASILEIRA DE ZOOTECNIA, 36., 1999, Porto Alegre. Anais... Porto Alegre: [s.n], 1999. CD-ROM.

FUKUJI, T. S.; FERREIRA, D. L.; SOARES, A. L.; PRETE, C. E. C.; IDA, E. I. Ácido fítico de híbridos de milho e alguns produtos industrializados. Acta Scientiarum. Agronomy, Maringá, v. 30, n. 1, p. 31-35, 2008.

GARDONI, B. L. K.; SATO, M. E. O.; PONTAROLO, R.; NORONHA, L.; REICHERT, A.; SERAFINI, S. Z. Avaliação clínica e morfológica da ação da hidroquinona e do ácido fítico como agentes despigmentantes. Acta Farmaceutica Banaerense, Buenos Aires, v. 23, n. 3, p. 297-303, 2004.

GODOY, S.; HERNÁNDEZ, G.; CHICCO, C. Efecto de la suplementación de fitasa microbial en la utilización de fósforo fítico en pollos de engorde alimentados con dietas a base de maíz - soya. Revista Científica, Maracaibo, v. 12, n. 2, p. 519-523, 2002.

GORDON, R. W.; ROLAND, D. A. Influence of supplemental phytase on calcium and phosphorus utilization in laying hens. Poultry Science, Champaign, v. 77, n. 1, p. 290-294, 1998.

GUILLERMO, E. S.; CARCÍA, M. C.; MARTÍNEZ, A. P.; ALCORTA, M. G.; PÉREZ, C. B.; BARRERA, E. M. Nivel óptimo biológico y econômico de fósforo en gallinas leghorn blancas en el segundo ciclo de postura. Revista Agrociência, Montecillo, v. 38, n. 6, p. 593-601, 2004.

HAMILTON, R. M. G. Methods and factors that affect the measurement of egg shell quality. Poultry Science, Champaign, v. 61, n. 6, p. 2022-2039, 1982.

JALAL, M. A.; SCHEIDELER, E. S. Effect of supplementation of two different sources of phytase on egg production parameters in laying hens and nutrient digestibility. Poultry Science, Champaign, v. 80, n. 10, p. 1463-1471, 2001. 
JENSEN, L. S.; CHANG, C. H.; WILSON, S. P. Interior egg quality: improvement by distillers feeds and trace elements. Poultry Science, Champaign, v. 57, n. 3, p. 648-654, 1978.

KESHAVARZ, K. Nonphytate phosphorus requirement of laying hens with and without phytase on a phase feeding. Poultry Science, Champaign, v. 79, n. 4, p. 748763, 2000.

LEE, B. J.; HENDRICKS, D. G. Phytic acid protective effect against beef round muscle lipid peroxadation. Journal of Food Science, Chicago, v. 60, n. 2, p. 241244, 1995.

LIM, H.; NAMKUNG, H.; PAIK, I. K. Effects of phytase supplementation on the performance, egg quality, and phosphorous excretion of laying hens fed different levels of dietary calcium and nonphytate phosphorous. Poultry Science, Champaign, v. 82, n. 1, p. 92-99, 2003.

LIMA, M. R.; SILVA, J. H. V.; ARAUJO, J. A., LIMA, C. B.; OLIVEIRA, E. R. A. Enzimas exógenas na alimentação de aves. Acta Veterinária Brasilica, Mossoró, v. 1, n. 3, p. 99-110, 2007.

LIU, N.; LIU, G. H.; LI, F. D.; SANDS, J. S.; ZHANG, S.; ZHENG, A. J.; RU, Y. J. Efficacy of phytases on egg production and nutrient digestibility in layers fed reduced phosphorus diets. Poultry Science, Champaign, v. 86, n. 11, p. 2337-2342, 2007.

LOAR, R. E.; SCHILLING, M. W.; MCDANIEL, C. D.; COUFAL, C. D.; ROGERS, S. F.; KARGES, K.; CORZO, A. Effect of dietary inclusion level of distillers dried grains with soluble on layer performance, egg characteristics, and consumer acceptability. Journal of Applied Poultry Research, Champaign, v. 19, n. 1, p. 3037, 2010.

MATEOS, G. G.; SELL, J. L. Influence of fat and carbohydrate source on rate of food passage of semi purified diets for laying hens. Poultry Science, Champaign, v. 60, n. 12, p. $2114-2119,1981$.

MATEOS, G. G.; SELL, J. L.; EASTWOOD, J. A. Rate of food passage (transit time) as influenced by level of supplemental fat. Poultry Science, Champaign, v. 61, n. 1, p. 94-00, 1982.

MOROS, E. E.; DARNOKO, D.; CHERYAN, M.; PERKINS, E. G.; JERRELL, J. Analysis of xanthophylls in corn by HPLC. Journal of Agricultural and Food Chemistry, Washington, v. 50, n. 21, p. 5787-5790, 2002.

O'DELL, B. L.; BOLAND, A. R. Complexation of phytase with proteins and cations in corn germ and oilseed meals. Journal of Agricultural and Food Chemistry, Washington, v. 24, n. 4, p. 804-808, 1976.
PANDA, A. K.; RAO, S. V. R.; RAJU, M. V.; BHANJA, S. K. Effect of microbial phytase on production performance of while leghorn layers fed on a non-phytate phosphorus. Poultry Science, Champaign, v. 46, n. 4, p. 464-469, 2005.

PINTAR, J.; BUJAN, M.; HOMEN, B.; GAZIĆ K.; SIKIRIĆ, M.; ČERNYT. Effects of supplemental phytase on mineral content in tibia of broilers fed cereal based diets. Czech Journal of Animal Science, Prague, v. 50, n. 2, p. 68-73, 2005.

RAVINDRAN, V.; MOREL, P. C.; PARTRIDGE, G.; HRUBY, M.; SANDS, J. S. Influence of an Escherichia coli derived phytase on nutrient utilization in broiler starters fed diets containing varying concentrations of phytic acid. Poultry Science, Champaign, v. 85, n. 1, p. 82-89, 2006.

ROSTAGNO, H. S.; ALBINO, L. F. T.; DONZELE, J. L.; GOMES, P. C.; FERREIRA, A. S.; OLIVEIRA, R. F.; LOPES, D. C. Tabelas brasileiras para aves e suinos: composição de alimentos e exigências nutricionais. 2. ed. Viçosa, MG: Universidade Federal de Viçosa, 2005. 186 p.

SAMLI, H. E.; SENKOYLU, N.; AKYUREK, H.; AGMA, A. Using rice bran in laying hen diets. Journal Central European Agriculture, Zagreb, v. 7, n. 1, p. 135140, 2006.

SCOTT, M. L.; NESHEIM, M. C.; YOUNG, R. J. Nutrition of the chicken. 3. ed. Ithaca: M.L Scott Associates, 1982. $562 \mathrm{p}$.

SELLE, P. H.; RAVINDRAN, V. Microbial phytase in poultry nutrition. Animal Feed Science and Technology, Netherlands, v. 135, n. 1, p. 1-41, 2007.

SILVA, D. J.; QUEIROZ, A. C. Análise de alimentos, métodos químicos e biológicos. 2. ed. Viçosa, MG: Universidade Federal de Viçosa, 2002. 235 p.

SILVERSIDES, F. G.; SCOTT, T. A.; KORVER, D. R.; AFSHARMANESH, M.; HRUBY, M. A study on the interaction of xylanase and phytase enzymes in wheatbased diets fed to commercial white and brown egg laying hens. Poultry Science, Champaign, v. 85, n. 2, p. 297-305, 2006.

SOARES, A. L.; OLIVO, R.; SHIMOKOMAKI, M.; IDA, E. I. Synergism between dietary vitamin e and exogenous phytic acid in prevention of warmed-overflavour development in chicken Pectoralis major $\mathrm{M}$. Brazilian Archives of Biology and Technology, Curitiba, v. 47, n. 1, p. 57-62, 2004. 
SOTO-SALANOVA, M. F.; WATT, C. L. Uso de enzimas para alcanzar el máximo potencial de las materias primas para dietas de avicultura. Minneapolis: Midwest Poultry Federation Convention, 1997. CD-ROM.

STADELMAN, W. J.; COTTERIL, O. J. Egg science and technology. 3. ed. New York: Food Products Press, 1986. 449 p.

TANGENDJAJA, B.; CHUNG, T. K.; BROZ, J. Effects of different sources of microbial phytase on production performance of brow-egg layers fed diets containing a high level of rice bran. Journal Applied Poultry Research, Champaign, v. 11, n. 2, p. 212-216, 2002.

UNIVERSIDADE FEDERAL DE VIÇOSA - UFV. SAEG - Sistema de análises estatísticas e genéticas. Versão 8.0. Viçosa, MG, 2000. 142 p.

VIEIRA, A. R.; RABELLO, C. B. V.; LUDKE, M. C. M. M.; DUTRA JÚNIOR; W. M.; TORRES, D. M.; LOPES J. B. Efeito de diferentes níveis de inclusão de farelo de arroz em dietas suplementadas com fitase para frangos de corte. Acta Scientiarum. Animal Sciences, Maringá, v. 29, n. 3, p. 267-275, 2007.

VIEIRA, R. S. A.; BERTECHINI, A. G.; FIALHO, E. T.; SANTOS, C. D.; TEIXEIRA, A. S. Desempenho e qualidade de ovos de poedeiras comerciais de segundo ciclo alimentadas com rações contendo fitase. Revista Ciência e Agrotecnologia, Lavras, v. 25, n. 6, p. 14131422, 2001.

WEAVER, C. M.; KANNAM, S. Phytate and mineral bioavailability, In: REDDY, N. R.; SATHE, S. K. Food Phytates, Florida: CRC Press, 2002, p. 25-51, 2002.

WU, G.; LIU, Z.; BRYANT, M. M.; ROLAND, D. A. Comparison of natuphos and phyzyme as phytase sources for commercial layers fed corn-soy diet. Poultry Science, Champaign, v. 85, n. 1, p. 64-69, 2006. 